\title{
ANALISIS PENGARUH NILAI SPIRITUAL ZAKAT TERHADAP KESEJAHTERAAN MUZAKKI MELALUI PERILAKU IHSAN
}

\author{
Zahida I'tisoma Billaha \\ aEkonomi Syariah, Fakultas Ekonomi dan Bisnis Islam, Universitas Islam Zainul Hasan Genggong \\ Probolinggo \\ Email: zahidafe@gmail.com
}

\begin{abstract}
Introduction: The importance of this research so that Muslim entrepreneurs realize the importance of obligations in issuing business zakat. And after they give zakat, it is expected that their behavior will be better in everyday life, especially in doing business so that they have a sociopreneurship entrepreneurial spirit. Therefore, the establishment of entrepreneur sociopreneurship through different activities by exploring spiritual values in issuing zakat is applied in business activities.

Methods: The analysis method in this research uses quantitative approach with measurement method using path analysis. The population used in this study was taken randomly, namely in the entrepreneurs in the field of culinary, services, and fashion in the city of Malang through the Ministry of Religious Affairs of Malang City. The number of samples amounted to the number of questions contained in the questionnaire multiplied by 5 which amounted to 110 entrepreneurs. With this approach, muzakki (entrepreneurs) are given a statement about spiritual motivation in issuing zakat in the form of values contained in zakat, namely: 1) the value of tawhid, 2) the value of humanity, 3) the value of belief in the existence of life after death.

Results: Based on this, the results found in the field and measurement using the analysis of the path, that the spiritual value of zakat can have a direct effect on the welfare of muzakki with a coefficient of determination of 0.64 while the indirect influence of spiritual value of zakat on the welfare of muzakki through ihsan behavior with a coefficient of determination of 0.38 because the person who spends zakat does not really understand the essence of spiritual value contained in zakat. Factors of wealth, descent, culture, education and the environment that make up a person is very determined in issuing zakat.
\end{abstract}

Keywords: spiritual value of zakat, Ihsan behavior, welfare

\section{PENDAHULUAN}

Ibadah zakat sebagai ibadah yang berhubungan dengan Allah swt dan sesama manusia menjadi pijakan dalam kebermaknaan hidup mereka untuk meningkatkan sikap kepedulian mereka terhadap sesame sebagai jalan untuk meraih pahala dan ridho Allah swt sehingga kehidupan mereka menjadi sejahtera baik secara lahir maupun bathin serta materiil. Kaitannya dengan dimensi moral dalam zakat terkandung nilai-nilai spiritual 
yang terdapat dalam zakat, ${ }^{1}$ yaitu antara lain: zakat merupakan perwujudan iman seseorang kepada Allah swt, mensyukuri nikmatnya, menumbuhkan akhlak mulia dengan memiliki rasa kemanusiaan yang tinggi, menghilangkan sifat kikir dan rakus, menumbuhkan ketenangan hati, menghilangkan sifat kikir dan rakus, zakat merupakan salah satu neraca untuk menimbang kekuatan iman seseorang serta menimbang sedalam apa kecintaannya yang tulus kepada Allah swt, karena secara tabiat atau kecenderungan manusia itu sangat cinta terhadap harta benda, zakat juga dapat sebagai terapi dalam menghilangkan sifat-sifat tercela yaitu iri, dengki/hasud yang mungkin muncul terutama kepada orang-orang kaya yang tidak memperdulikan mereka. Dengan zakat maka sesungguhnya kita telah mensucikan diri kita dari dosa, memurnikan jiwa (tazkiyah annafs), menumbuhkan akhlak mulia, murah hati, peka terhadap rasa kemanusiaan, mengikis sifat bakhil/kikir serta serakah, sehingga dapat menghadirkan ketenangan hati dan jiwa. Bagaimana kita dapat menumbuhkan sifat-sifat seperti diatas ? sebagai dasar pijakan adalah landasan keimanan yang kuat dalam hatinya (bertauhid), dengan kata lain kepentingan dunia (EQ) dan kepentingan spiritual (SQ) seimbang.

Yang kedua adalah dorongan untuk selalu berbuat baik kepada sesame dan dermawan terhadap kerabat. Yang perlu ditekankan disini adalah mengenai konsep muamalah kepada sesame manusia, bagaimana Allah menitipkan harta yang kita punya, bagaimana kita membelanjakan harta yang kita peroleh, karena dalam rezeki yang kita peroleh dari pekerjaan kita, terdapat hak-hak orang yang kurang mampu, maka Islam menganjurkan untuk berzakat, kemudian yang ketiga adalah percaya kehidupan setelah mati. Artinya harta yang kita peroleh saat ini merupakan harta titipan dari Allah swt, jika sudah meninggal, harta tersebut tidak dibawa ke liang kubur, maka nantinya diakhirat akan dipertanggungjawabkan untuk apa saja alokasi rezeki kita dan bagaimana cara mendapatkannya. Kesemua itulah merupakan nilai-nilai spiritual seseorang dalam mengeluarkan zakat, yang mana terkait dengan motivasi rohaniah seseorang.

Dalam penelitian ini yang menjadi objeknya adalah pengusaha muslim, dimana mereka diwajibkan mengeluarkan zakat perniagaan agar terbentuk jiwa entrepreneur yang sociopreneurship. Dengan nilai-nilai spiritual yang terkandung dalam zakat, diharapkan mereka dapat berperilaku ihsan yaitu memiliki kepribadian yang pantang menyerah, gigih, mandiri, inovatif, peka social, peduli dan memiliki empati yang tinggi terhadap masyarakat. Seorang socipreneur tidak hanya memikirkan aspek bisnis atau keuntungan semata, tapi juga cara agar bisnisnya dapat membawa manfaat bagi masyarakat dan lingkungan sekitarnya.dengan melihat kondisi seperti itu, kota Malang sebagai pelopor kota Industri yang banyak berdiri UMKM yang berkontribusi sangat besar. Dalam penelitian ini yang diteliti adalah muzaki (pengusaha UMKM yang muslim) yang membayar zakat di LAZ-LAZ yang terdapat dikota Malang serta pengaruhnya

\footnotetext{
${ }^{1}$ Hikmat Kurnia dan Hidayat, Panduan Pintar Zakat: Harta Berkah, Pahala Bertambah (Jakarta: Qultummedia, 2008), hlm 47-49.
} 
terhadap perilakunya serta kesejahteraan lahir dan bathinnya setelah mengeluarkan zakat.

\section{KAJIAN PUSTAKA}

1. Nilai Spiritual Zakat

a. Kesadran Tauhid (Eksistensi Tuhan)

Terkait dengan keimanan, maka seorang Muslim memiliki kewajiban dan keterikatan dengan agamanya, di antaranya adalah iman (meyakini Islam), amal (melaksanakan Islam), ilmu (mempelajari Islam), dakwah/jihad (menyebarluaskan dan membela Islam) dan sabar (tabah dalam ber-Islam). Humanitarianisme (paham yang mengajarkan tentang kepedulian sosial).

b. Humanitarianisme dapat diartikan sebagai suatu paham yang mengajarkan dan menekankan pentingnya kepekaan dan kepedulian untuk memberikan santunan, pertolongan dan bantuan terhadap masalah-masalah kemanausiaan bersama.

c. Percaya kehidupan setelah mati

Terkait dengan harta yang kita miliki, maka itu semua merupakan titipan (amanat) yang Allah berikan kepada kita. Orang yang mati tidak akan membawa hartanya ke laing lahat. Pangkat, gelar, kedudukan, bintang-bintang kebesaran, tongkat komando kekuasaan, jubah kebesaran, tahta dan harta benda yang manusia bangga-banggakan sebagai atribut-atribut duniawi ketika masih hidup di dunia dan menjadi gebyar symbol atau pesona status social bukan lagi merupakan symbol kebesaran atau kemegahan ketika menghadap Allah dan bukan pula merupakan bekal kematian untuk menghadap Allah. Bekal kematian adalah iman, takwa, karya-karya kebajikan, dan amal-amal kebaikan (termasuk amal puasa ramadhan).

2. Konsep Ihsan hubungannya dengan Etika dalam berbisnis etika yang harus diperhatikan diantara prinsip-prinsip etika dalam berbisnis adalah:

a. Bersandar pada ketentuan Tuhan (tauhid)

b. Jujur dalam takaran

c. Menjual barang yang baik mutunya

d. Dilarang menggunakan sumpah

e. Longgar dan bermurah hati

f. Membangun hubungan baik

g. Tertib administrasi

h. Menetapkan harga dengan transparan

3. Kesejahteraan menurut Ekonomi Islam

Kesejahteraan dalam fungsi matematisnya dapat dilihat dibawaha ini.

$$
\begin{aligned}
& \mathrm{Ki}=f(\mathrm{MQ}, \mathrm{SQ}) \\
& \mathrm{Ki}=\text { adalah kesejahteraan yang Islami (Islamic Welfare) }
\end{aligned}
$$


$\mathrm{MQ}=$ Kecerdasan Material (Material Quetient)

SQ = Kecerdasan Spiritual (Spiritual Quetient)

\section{METODE PENELITIAN}

Tehnik pengumpulan data yang digunakan seperti wawancara, penyebaran kuesioner, dan dokumentasi. Populasi penelitian adalah pengusaha muslim yang usahanya bergerak dalam bidang kuliner, fashion dan jasa di kota malang yang mengeluarkan zakat perniagaan. Sampel penelitian adalah sejumlah pertanyaan dalam angket penelitian sejumlah 22 item pertanyaan yang dikalikan 5 sehingga diperoleh sampel pengusaha muslim sebanyak 110 orang. Data yang dikumpulkan adalah data primer mellaui wawancara tertulis secara langsung dan melalui email (via angket online) yang disebarkan kepada komunitas-komunitas pengusaha muslim di kota Malang (KPMI). Berdasarakan tujuan penelitian, maka metode analisis data yang dgunakan dalam penelitian ini adalah path analisis, dengan terlebih dahulu melakukan uji reliabilitas dan uji validitas pada kuesioner yang digunakan untuk mengumpulkan data. Sedangkan untuk memaparkan masing-masing variabel dilakukanuji asumsi klasik seperti uji multikolinearitas, homoskedastisitas, uji kolmogorof-smirnov, uji linearitas.

\section{HASIL DAN PEMBAHASAN}

\section{Hasil}

1. Uji validitas dan realibilitas

Hasil uji validitas menunjukkan hasil korelasi semua instrument lebih $<0.05$ dan nilai validitas $>0.03$ analisis reliabilitas menunjukkan pada pengertian apakah instrument dapat mengukur suatu yang diukur secara konsisten dari waktu ke waktu. Ukuran dikatakan reliable jika ukuran tersebut memberikan hasil yang konsisten. Reliabilitas diukur dengan menggunkan metode cronbach alpha. Rumus cronbach alpha dikatakan reliable apabila nilai cronbach alpha lebih besar ( $>$ ) dari 0.60 (Ghozali, 2008:42)

2. Uji Asumsi Klasik

a. Uji multikolinearitas

Berdasarkan data hasil pengujian asumsi multikolinieritas, nilai VIF semua variabel bebas kurang dari 5, hal ini berarti variabel bebas yang digunakan dalam penelitian tidak terjadi multikolinieritas.

b. Uji heteroskedastisitas

\begin{tabular}{|l|c|c|c|}
\hline \multicolumn{1}{|c|}{ Variabel bebas } & r & sig & Keterangan \\
\hline Eksistensi Tuhan (X1.1) & 0.004 & 0.971 & Homoskedastisitas \\
\hline Kemanusiaan (X1.2) & -0.088 & 0.358 & Homoskedastisitas \\
\hline $\begin{array}{l}\text { Percaya kehidupan setelah mati } \\
\text { (X1.3) }\end{array}$ & -0.003 & 0.977 & Homoskedastisitas \\
\hline Perilaku Ihsan (X2) & -0.072 & 0.453 & homoskedastisitas \\
\hline
\end{tabular}


c. Autokorelasi

\begin{tabular}{|l|c|r|r|r|c|}
\hline Model & R & R Square & $\begin{array}{c}\text { Adjusted R } \\
\text { Square }\end{array}$ & $\begin{array}{c}\text { Std. Error of } \\
\text { the Estimate }\end{array}$ & $\begin{array}{c}\text { Durbin- } \\
\text { Watson }\end{array}$ \\
\hline 1 & $.779 \mathrm{a}$ & .607 & .592 & 1.084 & 2.121 \\
\hline
\end{tabular}

a. Predictors: (Constant), Perilaku Ihsan, Eksistensi Tuhan,

Kemanusiaan (Humanisme), Percaya Kehidupan Setelah Mati

b. Dependent Variable: Kesejahteraan Muzakki

Tabel diatas menunjukkan bahwasannya nilai dw diperoleh sebesar 2.121 itu artinya $1.65<\mathrm{dw}<2.35$, nilai 2.121 lebih kecil daripada $(<) 2.35$ artinya tidak terjadi autokorelasi.

d. Uji normalitas

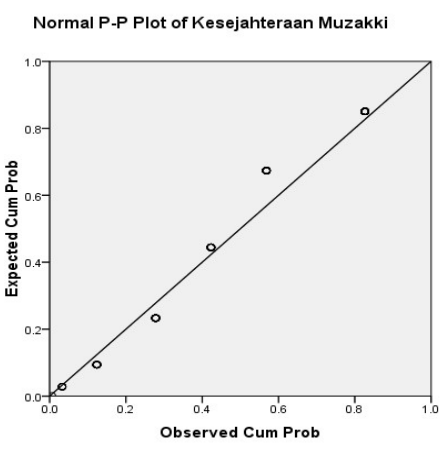

e. Uji Linearitas

\begin{tabular}{|l|l|l|l|l|l|}
\hline Variabel & R square & df & F & Sig & b1 \\
\hline
\end{tabular}




\begin{tabular}{|l|l|l|l|l|l|}
\hline $\mathrm{X} 1.1$ & 0.096 & 108 & 11.415 & 0.001 & 0.510 \\
\hline $\mathrm{X} 1.2$ & 0.410 & 108 & 75.032 & 0.000 & 0.752 \\
\hline $\mathrm{X} 1.3$ & 0.374 & 108 & 64.614 & 0.000 & 0.695 \\
\hline $\mathrm{X} 2$ & 0.496 & 108 & 106.095 & 0.000 & 0.439 \\
\hline
\end{tabular}

Dari hasil di atas diperoleh bahwasannya nilai sigf yaitu 0.001 untuk variabel X1.1 dan 0.000 untuk X1.2 sampai X2 yang artinya kurang dari $(<) 0.05$, maka asumsi linieritas terpenuhi.

f. Uji Path (Analisa Jalur)

Dari hasil penjabaran diatas, maka didapatkan ringkasan berupa pengaruh langsung dan tidak langsung dari bebrapa variabel, diantaranya yaitu:

Tabel 4.1

Hasil pengaruh langsung dan tidak langsung antar Variabel

\begin{tabular}{|l|l|l|l|}
\hline Pengaruh Variabel & \multicolumn{1}{|c|}{ Langsung } & $\begin{array}{c}\text { Tidak langsung } \\
\text { melalui (X2) }\end{array}$ & Total \\
\hline$\rightarrow \mathrm{Y}$ & 43 & & 43 \\
\hline$\rightarrow \mathrm{X} 2$ & 46 & & 46 \\
\hline$\rightarrow \mathrm{Y}$ & 06 & & 06 \\
\hline$\rightarrow \mathrm{X} 2 \rightarrow \mathrm{Y}$ & 8 & 23 \\
\hline
\end{tabular}
langsung:

Dibawah ini merupakan bagan koefisien jalur pengaruh langsung dan tidak

Bagan 4.2

Koefisien Jalur

P4 (0.38)

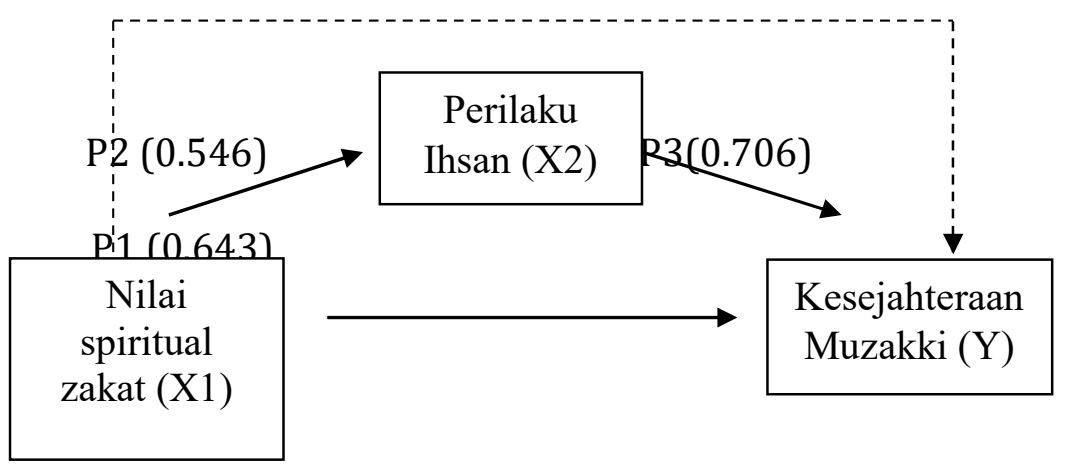

]Keterangan:

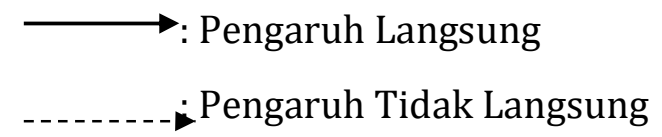




\section{Pembahasan}

1. Pengaruh langsung Nilai Spiritual Zakat terhadap Kesejahteraan Muzakki Berdasarkan hasil penelitian di lapangan serta hasil pengujian analisis jalur, menunjukkan bahwa varaibel nilai spiritual zakat mempunyai pengaruh langsung yang signifikan terhadap kesejahteraan muzakki $(p=0.000<0.05)$. yang mana nilai spiritual zakat mempengaruhi variabel kesejahteraan muzakki sebesar $40.7 \%$. Hasil penelitian tersebut mendukung penelitian yang dilakukan oleh Sutikno ${ }^{2}$ yaitu Sedekah menjadi instumen untuk meningkatkan kesejahteraan lahir dan bathin melalui transmisi iman taqwa.

2. Pengaruh langsung Nilai Spiritual Zakat terhadap Perilaku Ihsan Muzakki Berdasarkan hasil penelitian di lapangan dan hasil uji analisis jalur, maka didapatkan variabel nilai spiritual zakat mempunyai pengaruh langsung yang signifikan terhadap perilaku ihsan muzakki $(p=0.000<0.05)$. yang mana nilai spiritual zakat mempengaruhi variabel perilaku ihsan sebesar 29.1\%. hasil penelitian tersebut mendukung penelitian yang dilakukan oleh Sutikno ${ }^{3}$ yang menyatakan bahwa sedekah menjadi instrument meningkatkan kesejahteraan melalui transmisi perbaikan perilaku hidup informan terutama kejujuran, profesionalisme dan etos kerja tinggi". kemudian sedekah menjadi transmisi bagi manusia yang bebrfikir untuk merubah nasibnya melalui perbaikan perilaku hidup kearah yang lebih baik, yaitu melalui kejujuran, profesionalisme, dan etos kerja.

3. Pengaruh Langsung Perilaku Ihsan terhadap Kesejahteraan Muzakki Berdasarkan hasil penelitian di lapangan serta hasil pengujian analisis jalur, menunjukkan bahwa variabel perilaku ihsan muzakki mempunyai pengaruh yang signifikan terhadap kesejahteraan muzakki $(p=0.000<0.05)$. Perilaku mencerminkan akhlak (etika) seseorang. Apabila seseorang taat pada etika, berkecenderungan akan menghasilkan perilaku yang baik dalam setiap aktivitas atau tindakannya. Sebagai contoh, yaitu hasil dari wawancara dengan pengusaha tersebut ia tidak mengambil margin tinggi dalam menjual barangnya. Yang penting lancar dalam berdagang, dan harus yakin bahwa Allah swt akan memberikan rezeki kepada orang-orang yang selalu bersyukur. Itu artinya pengusaha tersebut menetapkan harganya secara toleran, artinya tetap memperhatikan hak pembeli.

4. Pengaruh tidak langsung nilai spiritual zakat terhadap kesejahteraan muzakki melalui perilaku Ihsan. Dari hasil peneitian di lapangan dan analisa jalur, didapatkan hasil bahwasannya nilai spiritual zakat, dapat mempengaruhi kesejahteraan muzakki melalui perilaku Ihsan sebesar 0.38. artinya nilai spiritual yang tertanam dalam diri seorang muzakki dalam mengeluarkan zakat, akan mempengaruhi tingkat kesejahteraan mereka, melalui perilaku bisnis yang ihsan

\footnotetext{
${ }^{2}$ Sutikno, memaknai perilaku muslim dalam bersedekah, disertasi FEB UB, tidak dipublikasi, 2011.

${ }^{3}$ Sutikno, memaknai perilaku muslim dalam bersedekah, disertasi FEB UB, tidak dipublikasi, 2011
} 
yang telah mereka lakukan. Ini sesuai dengan al-Qur'an surat al-Qashas yang mengatakan, jika kita ingin meraih kesejahteraan di dunia dan di akhirat, maka berlakulah Ihsan (baik) kepada sesame.

\section{KESIMPULAN}

1. Semakin tinggi nilai spiritual yang tertanam dalam diri seorang muzakki dalam mengeluarkan zakat, maka semakin tinggi pula tingkat keyakinan akan kesejahteraan dalam hidupnya.

2. Semakin tinggi nilai spiritual yang tertanam dalam diri seorang muzakki dalam mengeluarkan zakat, maka semakin meningkat (baik) pula perilakunya dalam berbisnis.

3. Semakin tinggi (baik) perilaku seorang muzakki dalam menjalankan bisnisnya, maka semakin tinggi pula tingkat kesejahteraan yang diraih dalam hidupnya.

4. Artinya para responden (pengusaha) tersebut untuk meraih kesejahteraan baik lahir maupun bathin, mereka berlomba-lomba untuk melakukan perilaku ihsan dalam berbisnis sesuai dengan etika Islam yang diajarkan Rasulullah saw dalam berdagang, yaitu sifat shiddiq, amanah, tabligh, fathonah.

\section{DAFTAR PUSTAKA}

\section{Buku:}

Aedy, Hasan. 2011. Teori dan Aplikasi Ekonomi Pembangunan Perspektif Islam Sebuah Studi Komparasi Yogyakarta : Graha Ilmu.

Al-Ba'ly, Abdul Al Hamid Mahmud. 2006. Ekonomi Zakat. Jakarta:PT Raja Grafindo Persada.

Arikunto, Suharsimi. 2010. Prosedur Penelitian : Suatu Pendekatan Praktik. Jakarta : PT Rineka Cipta.

Ashari, Rahmat Thohir, SEQ Spiritual Engineering Quotient. 2008. Yogyakarta :

\section{Jurnal:}

Achmad Muhammad, Jurnal MD vol II No. 1 Juli-Desember 2009

Amaliah, Ima. 2015. "Relevansi nilai religiusitas dalam berkonsumsi dengan kebahagiaan." Prosidding SNAPP, Sosial Ekonomi dan Humaniora.

Arif, Suyoto. 2012. "Konsumen Rasional dalam Perspektif Islam." Ejournal.unida.gontor.ac.id, Vol. 1, No. 1. 
Asdiyansyuri, Ulfiyani. 2016. "Analisis pengaruh pengeluaran zakat, infaq, dan shodaqoh terhadap kesejahteraan muzakki." International Journal of sosial and local economic governance, Vol. 2, No. 1.

Bachmid, gamsir. 2012. "Perilaku muzakki dalam membayar zakat mal." Jurnal Aplikasi Manajemen, Vol. 10, No. 20.

Djakfar. 2010. "Corporate sosial Responsibility aktualisasi ajaran islam dalam bisnis." Jurnal Ulul Albab:UIN malang, Vol. 11 No. 1. 